\title{
لفظ القسم ومرادفاته في السور المدنية
}

\section{Fitri Annisa Hayati}

\section{Mahasiswa Magister Pendidikan Bahasa Arab Universitas Negeri Malang}

Email : fitriannisahayati93@gmail.com

\begin{abstract} halafa and yahlifuna, special oath fala warabbika, nabtahil, yu'luna and ya'tali, syahadatin billahi and aiman. (2) In Madani surahs, the researcher finds that there are four function of the word oath and their synonyms, namely to throw away doubt, to strengthen the reason, to strengthen the statement and to define the law perfectly. (3) The contexts used to distinguish the word oath and its synonyms are linguistic and non-linguistic (situation) contexts
\end{abstract}

This research is meant to describe : (i) Various synonyms of the word oath in Madani surahs (2) The importance or the usage of the word oath and its synonyms in Madani surahs (3) The contexts of the word oath and its synonyms in Madani surahs. The research methodology used is qualitative descriptive. The results of the research are as follows : (1) There are 7 words as synonyms of the word oath in Madaniah surahs. They are aqsama and yuqsimu,

KEYWORD Oaths, Synonyms, Madani Surahs

بعدما ترى الباحثة أنواع معجزات القرآن السابقة فكانت تريد أن تتعمق في

دراستها حتى تعرف جميع مزاياه.بذلك، القرآن الكريم معجز خالد من عند الله وحمله التهله

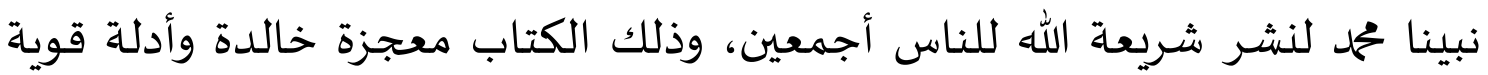

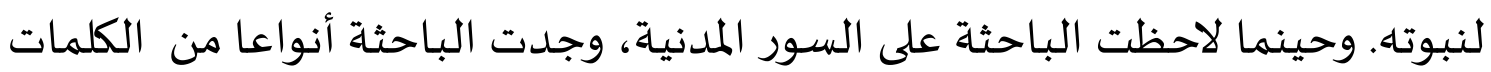

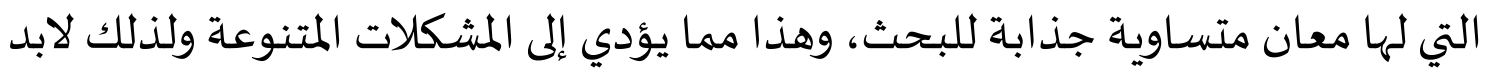


من أن تحللها الباحثة. والمشكلات التي تكون من ناحية علم الدلالة في المترادفات لها

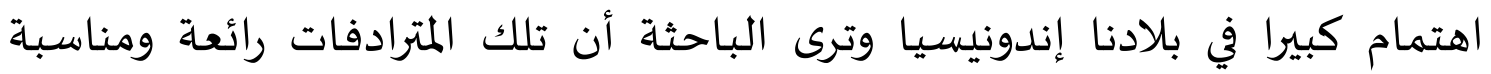
للتحليل.

السور المدنية لها مميزات موضوعية وخصائص الأسلوب، منها بيان العبادات،

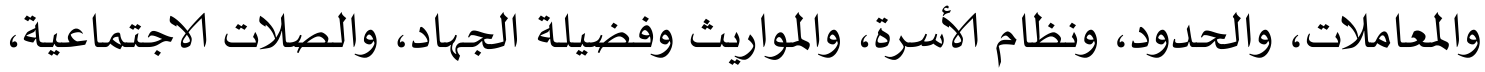
والعلاقات الدولية في السلم والحرب، وقواعد الحكم، ومسائل التشريح.

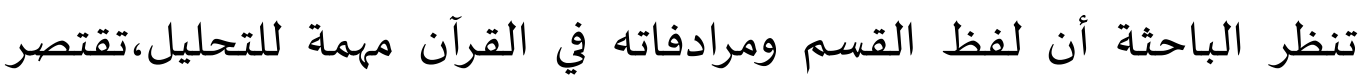
الباحثة في السور المدنية لأنها تريد أن تكمل البحث العلهي من قبل لسوكردي من ناحية

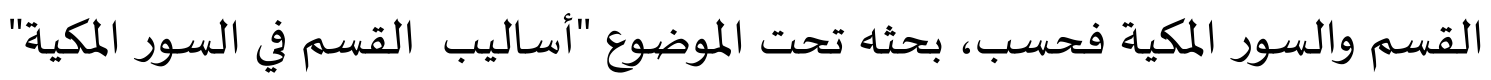

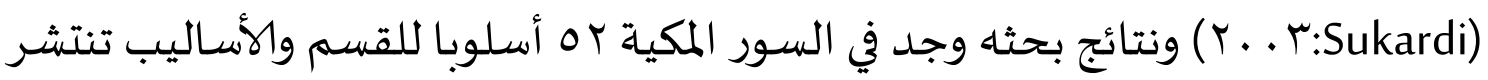

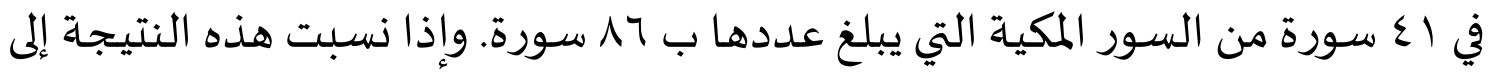

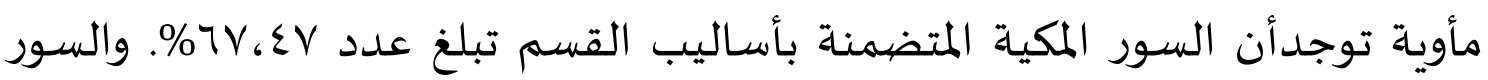

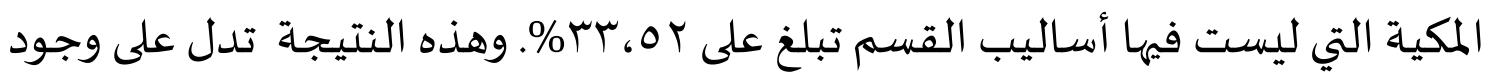

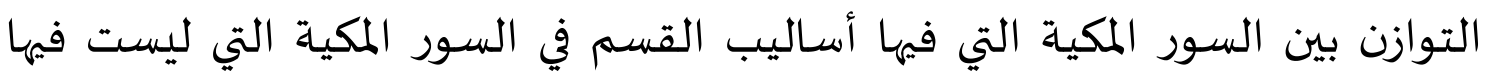
أساليب القسم.

توجد الاختلاف والامتثال في هذا البحث بالبحث السابق، يختلف هذا البحث عن البحث الأول في موضوع البحث، الباحث الأول يبحث في أساليب القسم وهذه البحث الباحثة تبحث في لفظ القسم ولكن كلاهما يتساويان في السور القرآن ويتكاملان بعضها بعضيا.

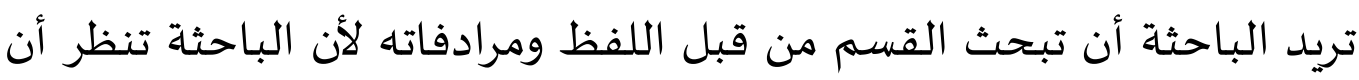
الأيات القرآنية لها آيات متساويا في معاني باللغة الإندونيسية ولكن الإن الأصلي غير متساويا

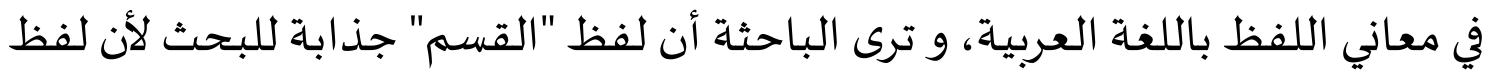

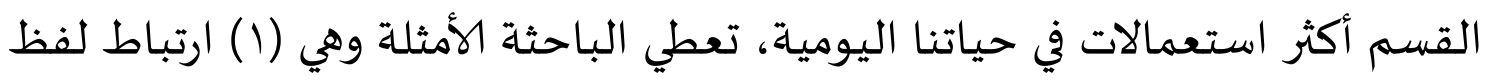

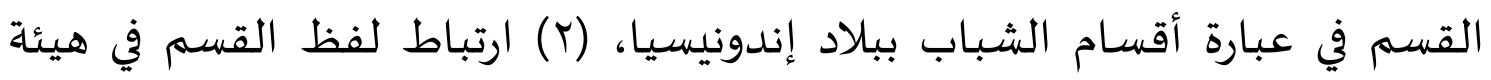
التحكيم في المحاكمة، (ץ) ارتباط لفظ القسم في عبارة الوعد. لذلك تختار الباحثة هذالموضيوع وهو "لفظ القسم ومرادفاته في السور المدنية". 
فالهدف لهذالبحث العلهي هو: وصف لفظ القسم ومرادفاته في السور المدنية، وصف فوائد لفظ القسم ومرادفاته في السور المدنية، وصف السيات وهياق الذي استخدم فياه لفظ القسم ومرادفاته في السور المدنية.

\section{نمّربات}

\section{تعريف القسم وصيغته}

الأقسام: جمع قسم: بفتح السين، بمعنى الحلف واليمين، والصيغذأأصلية

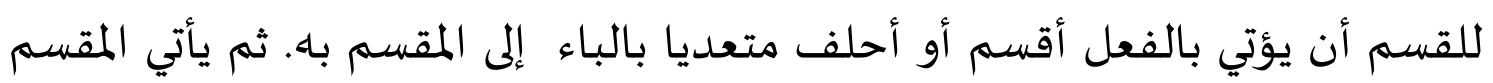

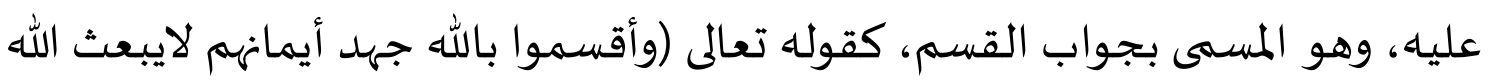

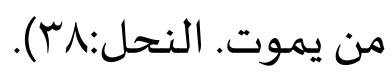
قال (الشاطئ في أسراري وعين، 1997:باتج) أن الألفاظ المترادفات في القرآن لا يستطيع أن تتفاسر وتتبادل. بناء على بحثاه، هو يستنتج أن القرآن يستعمل الألفاظ

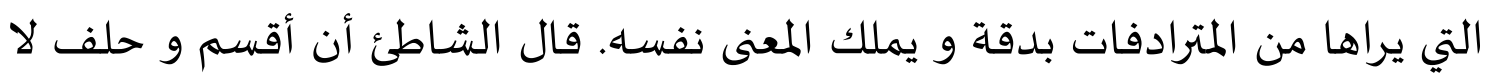

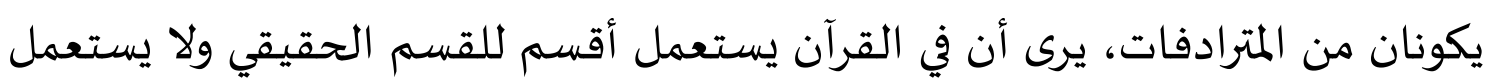
للزائف.أما حلف فيستعمل للقسم الزائف ويستعمل في القرآن للقسم الذي يتعلق بالجرائم.

فائدة القسم في القرآن

قال (جلال، . . . Y) أن فائدة القسم تختلف بأغراض القسم، قال جلال أن أغراض القسم هي الشيء الذي يريده المتكلم قبل القسم وأما فائدة القسم هي الشيء الذي يحصله المتكلم بعد القسم. وهو يقول أن أغراض القسم هي تقوية الكلام أن يقبل فيل فئل ويؤمن للسـامع أو المخاطب،يرى جلال أن القسم يحتاج في الكلام لأن السامع أو لون المخاطب سيعمل أحدا من الأمور الثلاثة التالية: 
أ- السـامع من الأشخاص المحايدة بالأخبار، لا يردد ولا ينكر الكلام يسمى بالكلام الابتدائي ،لا يحتاج الخبر إلى التوكيد والقسم. مثل (ذلكَ الكتابُ لَا رَبِّ فياِِ.

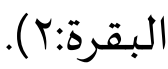
ب- يكون السامع مترددا للخبر ويحتاج إلى التأكيد، هذالحال يسمى بالكلام الطلبي

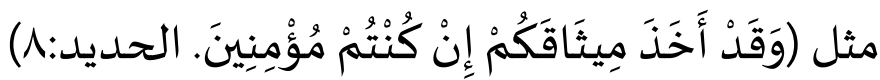
ج- يكون السامع منكرا للخبر، إن كان مقدار الإنكار قليل، يكفياء بالتوكيد فحسب

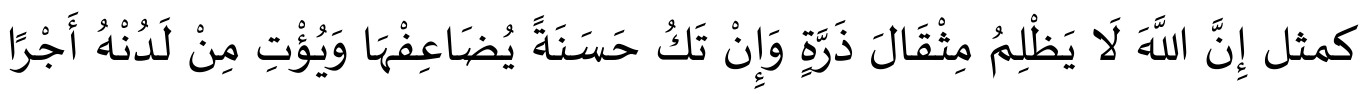
عَظِيمًا. النساء:.ع.وإن كان مقدار الإنكار كثير فيحتاج السامع إلى توكيدين أو

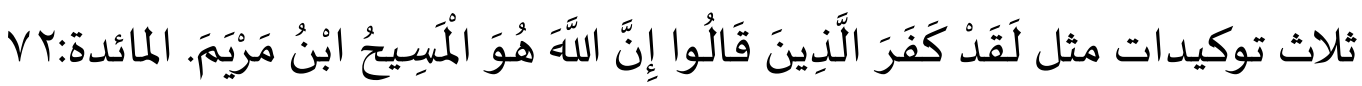

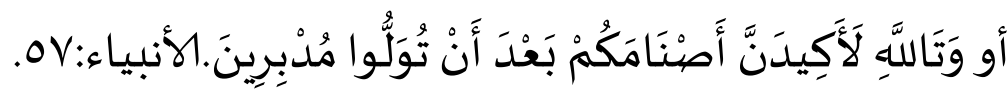

قال (جلال، . . . r) أن فائدة القسم ثلاثة، وهي: أ- يكون الخبر بالغا للسامع وهو لا يردّ الخبر ويتيقن أن الخبر صحيح لأن الخبر يؤكد بالقسم، لا سيما القسم بلفظ الجلالة. ب- يشعر المخبر بالفرح والسعادة لأنه يستطيع أن يجعل السامع متيقنا بالخبر بوسيلة القسم أو التأكيد الأخر. هذاالحال يختلف قبل وجود القسم وبعد وجوده لأن قبل وجود القسم لا يقبل السامع الخبر. ج- قال الدكتور بكري الشيخ الأمين أن القسم بلفظ الجلالة أو اسماءه الأخرى يدل

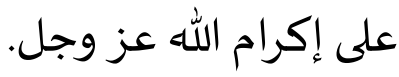
قال (جارم وأمين، 1999) أن لتوكيد الخبر أدوات كثيرة منها إنّ، أنّ، والقسم، ولام الابتداء، ونونا التوكيد، وأحرف التنبيه، والحروف الزائدة، وقد، وأما الشرطية. 


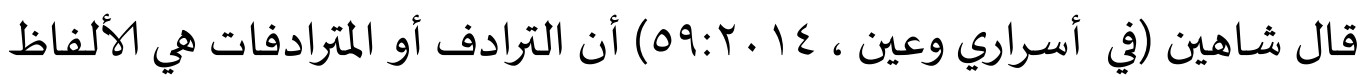
التي اختلفت صيغتها وتواردت على معنى واحد. و قال جاجا سودارما (في عين وأسراري، ع ا ـ ץ: ـ 7) أن طرق لتصنيف الكلمات المترادفات بثلاثة طرق وهي (1) استبد ال أو نسهى ب substitusi، (Y) الاعتراض أو نسمى ب pertentangan، و (r) تعيين الإضافي أو نسمى ب .penentuan konotasi

\section{تحديد السور المدنية عند العلماء}

قال القاضي أبو بكر ابن الطيب الباقلاني في ((الانتصار)) إنما يرجع في معرفة

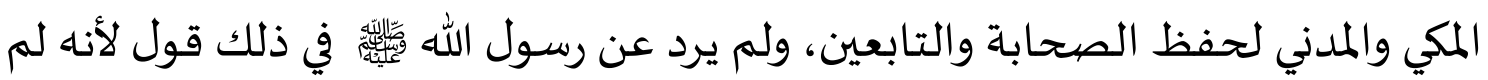
يؤمر باه، ولم يجعل الله علم ذلك من فرائض الأمة (قطان، . . . ؟ . . 7). قال الجعبري في قطان إذا يريد الإنسان لمعرفة المكي والمدني له طريقان: (1) سماعي، (Y) قياسي. ولا شك أن السماعي يعتمد على النقل، والقياسي يعتمد على إلى العقل، النقل والعقل هما طريقا المعرفة السليمة والتحقيق العلمي. أما تحديد السور المدنية (القطان، . . . ب:00) عشرون سورة: (1) سورة البقرة،

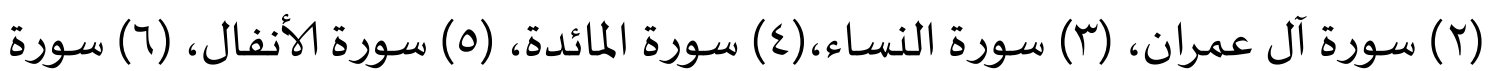

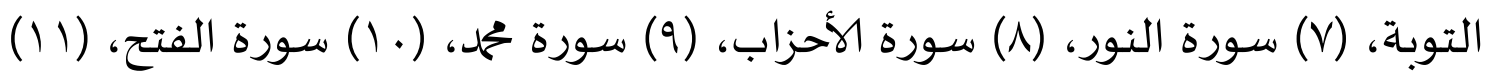

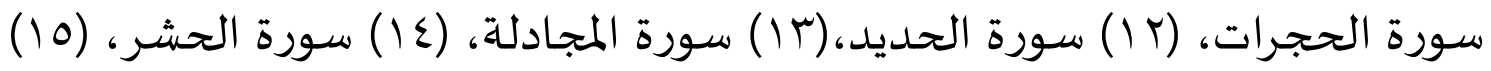
سورة الممتحنة، (17) سورة الجمعة، (IV) سورة المنافقون، (IN) سورة الطلاق، (19) سورة التحريم، (·r) سورة النصر. اعتمادا على ذلك، تجد الباحثة السور المدنية التي فهها لفظ القسم ومرادفاته فهي تسع سور : (1) سورة البقرة، (Y) سورة آل عمران، (؟)

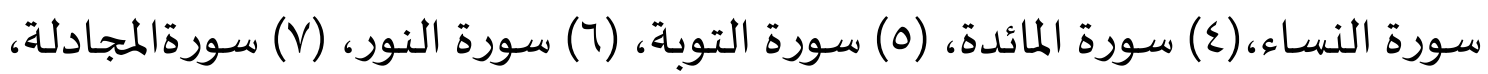
(^) سورة المنافقون، و(9) سورة التحريم. 


\section{نظرية السياق}

عرفت مدرسة لندن بما سمي بالمنهج السياقي contextual approach أو المنهج العملي operational approach. وكان زعيم هذا الاتجاه Firth الذي وضع تأكيدا كبيرا على الوظيفة الاجتماعية للغة، كما ضم الاتجاه أسماء مثل: Mc Intosh و و و و و Sinclair، و Mitchell. وعد Lyons أحدالتطورين الهامين المرتبطين بفيرث "نظريته

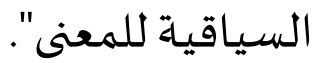

ومعنى الكلمة عند أصحاب هذه النظرية هو " استعمالها في اللغة"، أو "الطريقة

التي تستعمل بها"، أو "الدور الذي تؤديه". ولهذا يصرح فيرث يأن المعنى لا ينكشف إلا

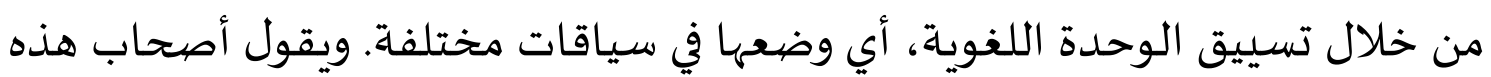
النظرية في شرح وجهاة نظرهم: "معظم الوحدات الدلالية تقع في مجاورة وحدات أخرى. وإن معاني هذه الوحدات لا يمكن وصفها أو تحديدها إلا بملاحظة الوحدات الأخرى التي تقع مجاورة لها". ومن أجل تركيزهم على السياقات اللغوية التي ترد فيها الكلمة وأهمية البحث عن ارتباطات الكلمة بالكلمات الأخرى نفوا أن يكون الطريق إلى معنى الكلمة هو رؤية المشار إليه، أو وصففه، أو تعريفه.

وعلى هذا فدراسة معاني الكلمات تتطلب تحليلا للسياقات والمواقف التي ترد فيها، حتى ما كان منها غير لغوي. ومعنى الكلمة - على هذا - يتعدل تبعا لتعدد السياقات التي

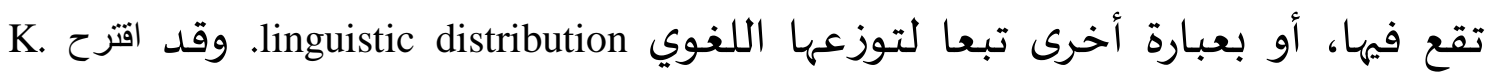
Ammer

$$
\text { ז }
$$




\section{طريقت البحث}

الأسلوب المستخدم في هذا البحث هو الأسلوب الوصفي. الأسلوب الوصفي هو الأسلوب الذي يعتمد على دراسة الواقع أو الظاهرة كما توجد في الواقع ويهتمّ بوصفها

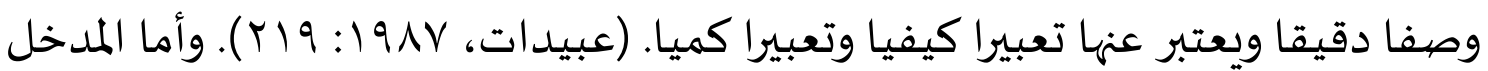
المستخدم في هذا البحث هو المدخل الكيفي، التعبير الكيفي يصف لنا الظاهرة ويوضح

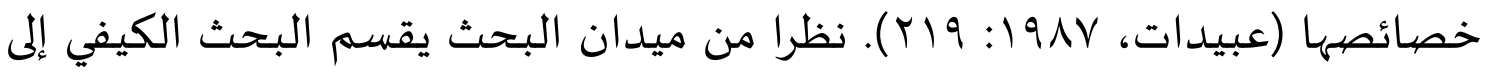

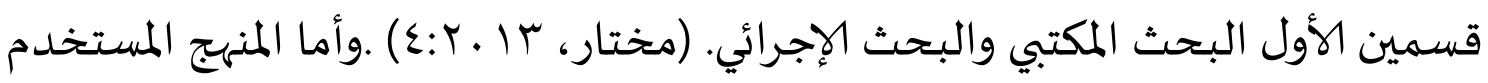
في هذا البحث فهو المنهج المكتبي.

والبيانات في هذا البحث (1) مرادفات لفظ القسم الموجودة في السور المدنية،

(Y) فوائد القسم الموجودة في السور المدنياة، (T) السياق الذي استخدم فياء لفظ القسم ومرادفاتاه في السور المدنية ، ومصيدر البيانات الأسـاسي في هذا البحث هو السور المدنية من القرآن الكريم. وأما المصادر الثانوية في هذا البحث فهي الكتب المتعلقة بأقسام القرآن والتفاسير . وأدوات البحث الأساسية في هذا البحث هي الباحثة نفسها لأها تقوم بالتصميم، والتأدياة، وجمع البيانات، والتحليل (Human Instrument) ،والتصحيح. وباعتبارها عاملة في جمع المعلومات، قال (Moleong، الوصفي الكيفي، طريقة جمع اليبانات المستخدمة هي المقابلة والملاحظة والتوثيق.أما طريقة جمع البيانات المستخدمة في هذا البحث هي التوثيق. للحصول على البيانات قامت الباحثة بالخطوات وهي: (1) قراءة الآيات التي فهيا لفظ القسم ومرادفاته في السور المدنية، (r) استخراج لفظ القسم ومرادفاته في السور المدنياة، (r) كتابة لفظ القسم ومرادفاته في السور المدنية في كراسة خاصة لتصحيح تحليل البيانات قامت الباحثة بالخطوات وهي: (1) استمرار الباحثة ومداومتها على قراءة وتفتيش البيانات بالدقة،(؟) القراءة المتكررة عن لفظ القسم 
ومرادفاته في السور المدنية للتعمق في مرادفاتها وفوائدها وسياقها، (r) إقامة الباحثة المناقشة مع الإخوة وأسـاتذة اللغة العربية المتخصصين في علم الدلالة لاستفادة من مصادر خارج البيانات التي تم تحليلها. وتفيد هذه الطريقة لمعرفة الأخطاءات من البحث.

\section{بحث ومناقشت}

مرادفات لفظ القسم في السور المدنية

كما كتبت الباحثة في الإطار النظري، أن تعريف المرادفات هو الألفاظ التي اختلفت صيفتها وتواردت على معنى واحد (شاهين في عينين وأسراري، ع ( ـ؟99)، اعتمادا على التعريف، تجد الباحثة مرادفات لفظ القسم في السور المدنية سبع ألفاظ وهي (1) لفظ أقسم ومشتقاته، (Y) لفظ حلف ويحلفون، (r) لفظ فلا + حرف القسم "و"، (ع) لفظ نبتهل بمعنى sumpah pocong، (0) لفظ يؤلون ويأتل بمعنى الإيلاء، (7) لفظ شهادات بالله، (V) لفظ الأيمان.

\section{فو ائد لفظ القسم ومرادفاته في السور المدنية}

وجدت الباحثة أربعة أنواع من فائدة القسم في السور المدنية، وهي تأكيد الأخبار في سورة ال عمران الأية ال7 وسورة النساء الأية ب7 وسورة التوبة الأية ب7، 707 و 90-97 97 وسورة المجادلة الأية ج|،ع| وم| وسورة المنافقون الأية r، مثلا في سورة النساءالأية

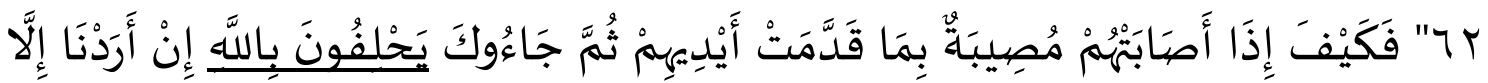
إِحْسَانًا وَتَوْفِيقًا". هذه الأيَة تفيد تأكيد الأخبار لأن فيها يقسم المنافقون أمام المؤمنين بلفظ يحلفون، وترى الباحثة أن هذا اللفظ يشير إلى القسم الزائف. وهذه الأية إنكار من الله عز وجل، على من يدعي الإيمان بما أنزل الله على رسوله وعلى الأنبياء الأقدمين ، المقسم في هذه الأية المنافقون وعلة القسم هي لا يريد المنافقون لمحمد إلا الإحسان 


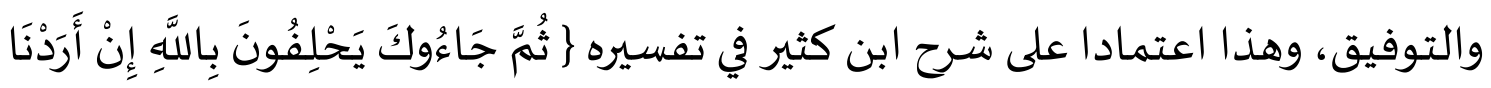

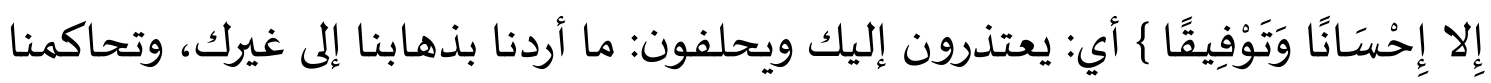

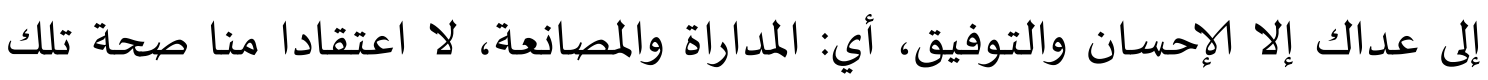

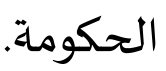

وتقرير الحكم في أكمل صورة في سورة البقرة الأية جبr-צrY وسورة ال عمران

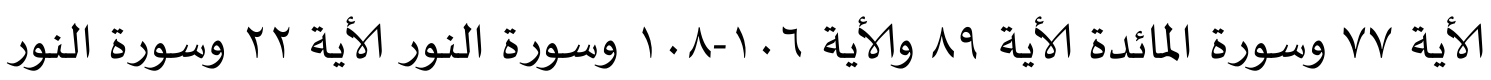

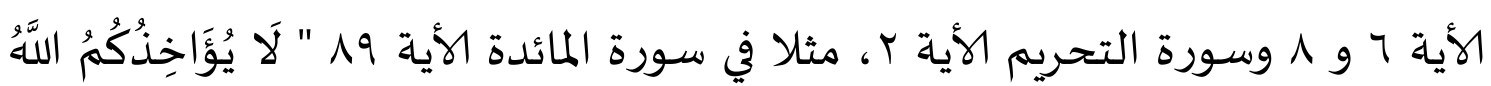

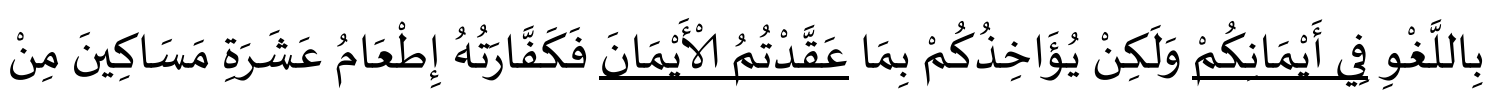

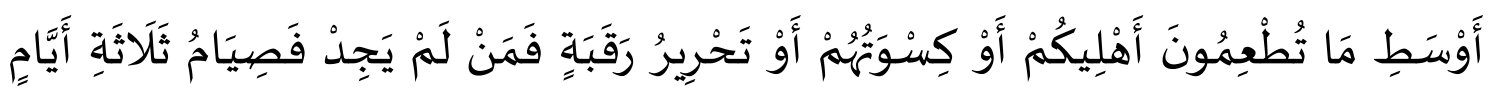

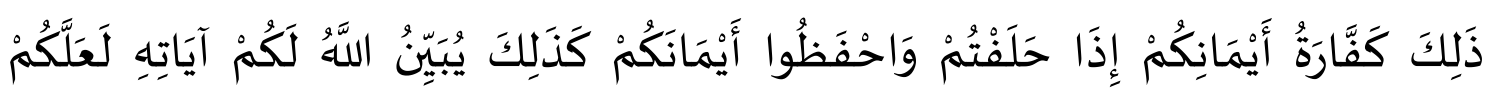

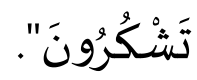

إن المقسم في هذه الأية هي "الله" وعلة القسم تقرير الحكم والحكم المقرر عن كفارة اليمين. وهذا مطابق بتفسير ابن كثير " وقال الشافعي: الواجب في كفارة اليمين

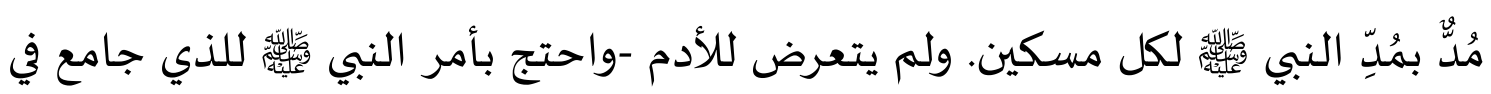

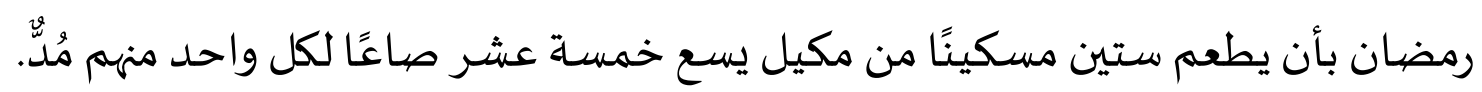
وإقامة الحجة في سورة التوبة الأية با-كا وسورة التوبة الأية عV، مثلا في

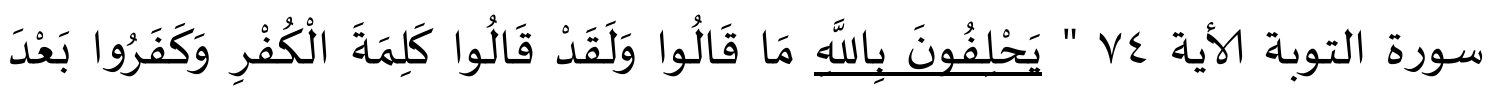

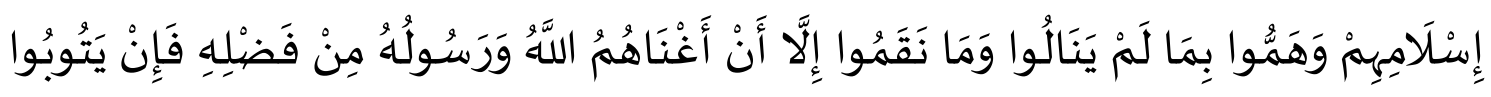

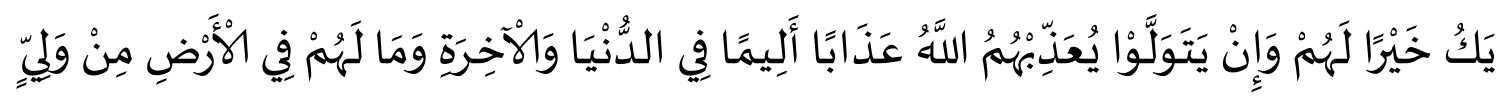
وَلَا نَهِيرٍ". المقسم منها المنافقون وعلة القسم ليحمي نفس المنافقين وترى أن هذه الأية تفيد إقامة الحجة لأن في هذه الأية مجادلة بين المنافقين والمؤمنين وفيها خيار من الله إن كانوا يريدون التوبة أم يريدون أن يتولوا. وهذا مطابق بتفسير ابن كثير " وذاك حين

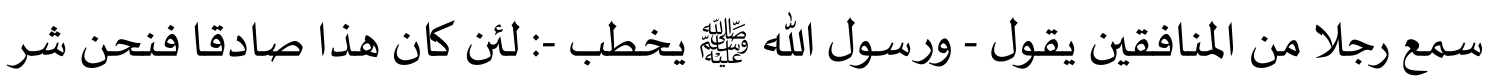


من الحمير، فقال زيد بن أرقم: فهو والله صادق، ولأنت شر من الحمار. ثم رُفح ذلك إلى

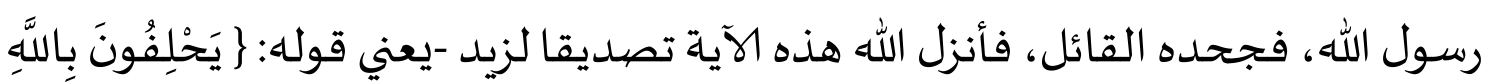
مَا قَالْوا \{ الآيَة".

وإزالة الشكوك في سورة النساء الأية 70 وسورة المائدة الأية به وسورة النور

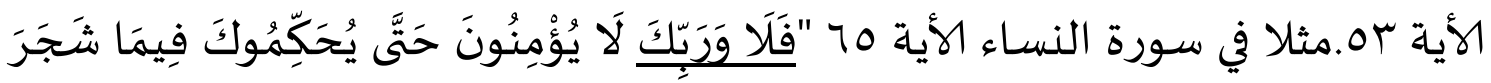

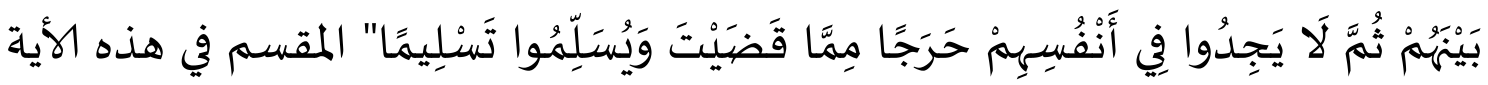
الله نفساه وعلة القسم إزالة شكوك المنافقين. وهذا مطابق بتفسير ابن كثير "وقوله:

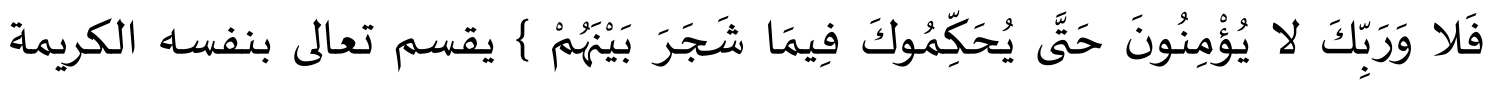

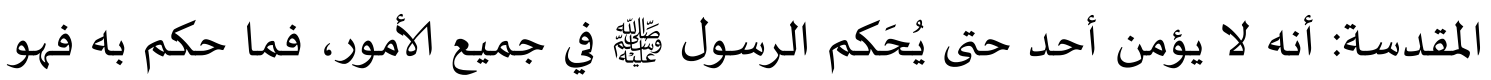

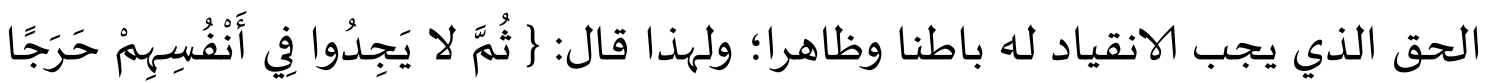

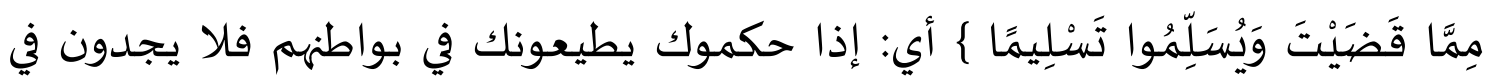
أنفسهم حرجا مما حكمت باه، وينقادون له في الظاهر والباطن فيسلمون لذلك تسليما كليا من غير ممانعة ولا مدافعة ولا منازعاة، كما ورد في الحديث: "والذي نفسي بيده لا يؤمن أحدكم حتى يكون هواه تبعا لما جئت بهاء.

\section{السياق الذي استخدم فيه لفظ القسم ومرادفاته في السور المدنية}

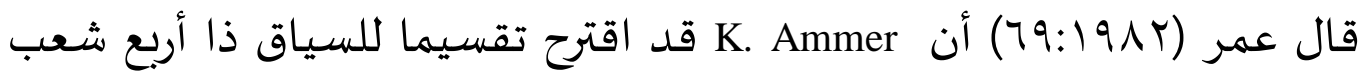
يشمل : (1) السياق اللغوي، (Y) السياق العاطفي، (Y) سياق الموقف، (ع) السياق الثقافي. ولكن في هذا البحث، تبحث الباحثة نوعين من السياق الأربعة، وهما السياق اللغوي وسياق غير اللغوي (سياق الموقف).

السياق اللغوي

قال عمر (79: ب 1919) أن السياق اللغوي هو الكلمات التي تقع في سياقات لغوية متنوعة.تنظر الباحثة السياق اللغوي في هذا البحث من الصيغة والإعراب وحرف 
القسم. تحلل الباحثة اللفظ الأول وهو بفعل أقسم ويقسم، ترى الباحثة لفظ أقسموا بالله من فعل ماضي والعنصر اللغوي الأخر الذي يشتركه هو لفظ "جهد أيمانهم" و قيّم المعنى من لفظ أقسموا بالله هو قسم المنافقين الذي يقرر المؤمنين. و ترى الباحثة لفظ يقسمان بالله من فعل مضارع ماضي والعنصر اللغوي الأخر التي تشتركه هو جملة شرطية و قيّم المعنى من لفظ يقسمان بالله هو قسم المؤمنين للشهادة. تحلل الباحثة اللفظ الثاني وهو بفعل حلف ويحلفون. ترى الباحثة لفظ يحلفون بالله من فعل مضارع والعناصر اللغوية الأخرى التي تشتركه جملة شرطية وجملة خبرية وجملة إنكارية و قيّم المعنى من لفظ يبحث المنافقون عن الحجة الكثيرة بالقسم. وترى الباحثة لفظ حلفتم من فعل ماضي ولا توجد العنصر اللغوي الأخر لأن الباحثة وجدت أية واحدة في سورة المدنية وهي في أخر أية و1 من سورة المائدة وقيّم المعنى من لفظ حلفتم هو بعض الشرح من كفارة القسم. تحلل الباحثة اللفظ الثالث وهو لفظ الأيمان من اسم الجامد والعنصر اللغوي الأخر هو جملة خبرية وقيم المعنى من لفظ الأيمان القسم يستطيح أن يستعمل في العهد و الوصيية.

تحلل الباحثة اللفظ الرابع وهو لفظ فلا وحرف القسم "و"، هذا اللفظ من الصيغة الخاصة التي تجد الباحثة في السور المدنية، لأن تلك الصيغة أحد من سبعة صيخ في أقسم الله تعالى بنفسـ في القرآن. وإعراب لفظ فلا وربك لا يؤمنون، يصير فاء استئنافية واللام مزيدة لتأكيد القسم، الواو حرف قسم وجر، ربك مجرور، الجار والمجرور متعلقان بمحذوف تقديره "أقسم".

تحلل الباحثة اللفظ الخامس وهو لفظ نبتهل من اللفظ الأسـاسي "البهلة". تنظر الباحثة أن صيغة هذا اللفظ من فعل المضارع و عندما ننظر القرآن بترجمة اللغة الإندونيسية، لا نجد معنى "قسم" في هذ اللفظ، ولكن عندما ننظر من حيث سياق هذا اللفظ، نستطيع أن نساوى بلفظ حلف وهو القسم الزائف والضيعيف، ترى الباحثة أن 
هذااللفظ يساوى بقسم pocong. وترى الباحثة أن سياق الأية القرآنية (ثُمَّ نَبْتهِلْ

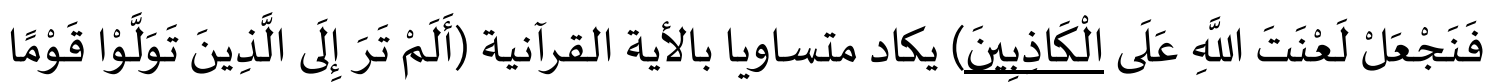

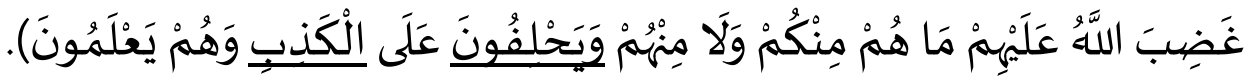
تحلل الباحثة اللفظ السادس وهو لفظ يؤلون ويأتل. تنظر الباحثة أن صيغة هذين اللفظين من فعل المضيارع، قال الدروشي في كتابه "إعراب القرآن وبيانه" أن لفظ (يأتل) في المختار من لفظ وآلى يؤلي إيلاء بمعنى حلف وتألي وأتلى مثله؟ قلت: ومنه قوله تعالى (ولا يأتل أولو الفضل منكم) والألية بمعنى اليمين، وجمعها ألايا، وتنظر الباحثة أن لفظ يؤلون ويأتل من قسم خاص لأن هما بمعنى الإيلاء.

\section{السياق غير اللغوي (سياق الموقف)}

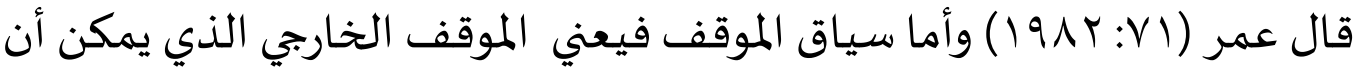
تقع فيه الكلمة. تحلل الباحثة السياق الذي استخدم فياء لفظ القسم ومرادفاتاه في السور المدنية من ناحية مقتضى الحال بالنظر إلى سياق مضمون الأية التي فيها لفظ القسم ومرادفاته في السور المدنية و مميزات لفظ القسم ومرادفاته في السور المدنية

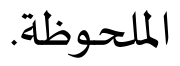

تنظر الباحثة سياق مضمون الأية التي فيها لفظ القسم ومرادفاته في السور المدنية بمساعدة القرآن وترجمته باللغة الإندونيسية وتنقسم الباحثة عشرة أقسام ،

1. السياق يقص عن قسم المنافقين، ترى الباحثة أن هذا السياق من السياق

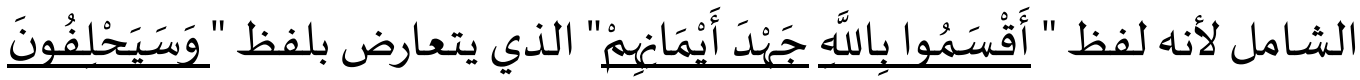

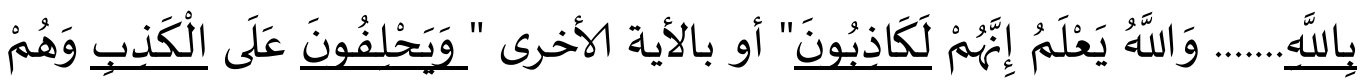
يَعْلَمُونَ"بهذا الاعتراض ترى الباحثة أن لفظ أقسم يتعارض في استعمال 
القسم، أما لفظ أقسم فيستعمل في القسم القوي وأما لفظ يحلفون فيستعمل في القسم الزائف،

r. السياق يقص عن قسم للموارث أو للوصية، تعتمد الباحثة هذا السياق على الى تفسير الجلالين وتجد الباحثة مثال الأية من لفظ يقسمان بمعنى يحلفان في

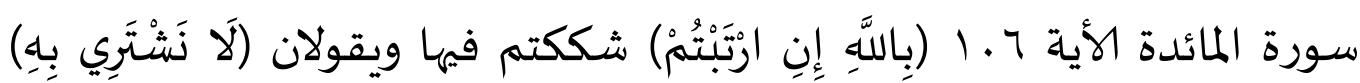

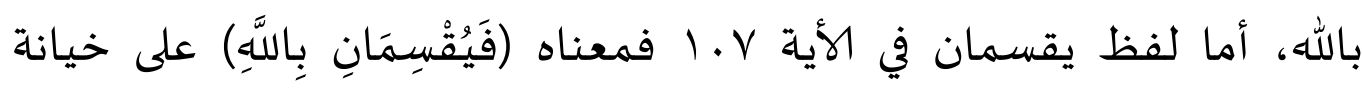
الشاهدين ويقولان (لشهادتنا) اي يميننا (أحق) بمعنى أصدق. وأما الشرح من

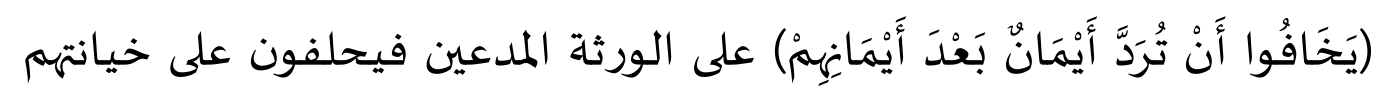
وكذبهم فيفتضحون ويغرمون فلا يكذبوا.

r. السياق يقص عن قسم للوعد، قال المحلي والسيوطي (دون سنة:10V) وتجد الباحثة مثال الأية من لفظ أيمانهم في سورة التوبة الأية rا بمعنى مواثيقهم ولفظ (أهم لا أيمان) بمعنى عهود وكذلك لفظ أيمانهم في الأية با بمعنى عهودهم،و في أول سورة ال عمران الأية VV (إن الذين يشترون) بمعنى

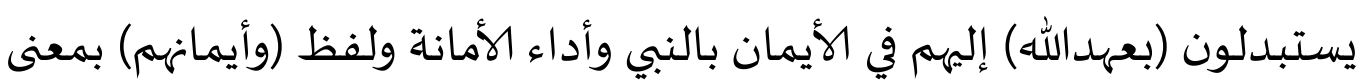
حلفهم باء تعالى كاذبين، ع. السياق يقص عن القسم بغير قصد أونسمى باللغو، ترى الباحثة أن هذا السياق من نص صريح في سورة البقرة الأية OY T و أول أية 19 من سورة المائدة ، الله يشرح أنه لا يحكم الناس بسبب القسم لا يقصيد ولكن يحكم الله بما

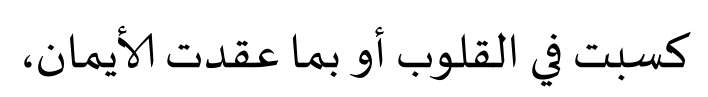
0. السياق يقص عن القسم بقصيد، تجد الباحثة في وسط الأية 19 من سورة

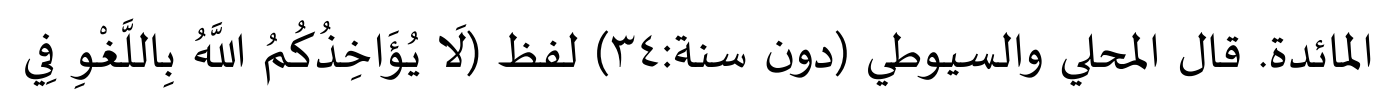
أَيْمَانِكُمْم) وهو ما يسبق إليه اللسان من غير قصيد الحلف نحو لا والله وبلى والله 


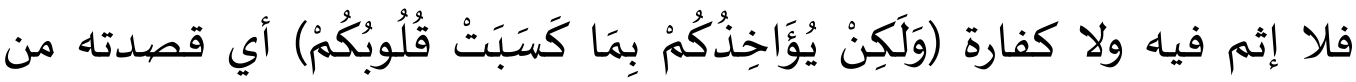
الأيمان إذا حنثتم

7. السياق يقص عن قسم الزوج، ترى الباحثة أن لفظ يؤلون في سورة البقرة الأية 7r له Fr علاقة بالأيتين السابقين. كما يشرح المراغي في تفسيره ثلاث ألفاظ مهمة في هذه الأية الثلاثة وهي: (1)الأيمان، (Y) واللغو، (r) والإيلاء. V السياق يقص عن تحلة القسم،تعتمد الباحثة شرح هذه الأية على تفسير

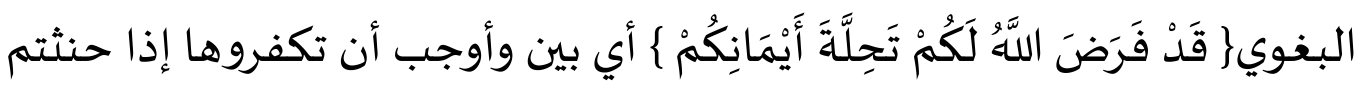

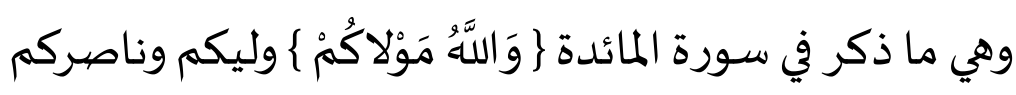
1. السياق يقص عن قسم pocong، ترى الباحثة أن وظائف قسم pocong لإزالة الشكوك خاصية لاكتشاف الكذب. وترى الباحثة أن سياق الأية القرآنية (ثُمَّم

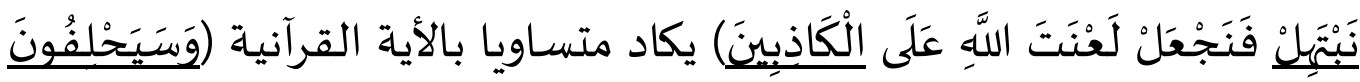

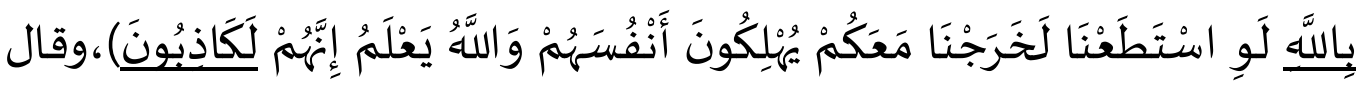
المحلي والسيوطي (دون سنة:هـ-عه) لفظ (ثم نبتهل) بمعنى نتضرع في الدعاء

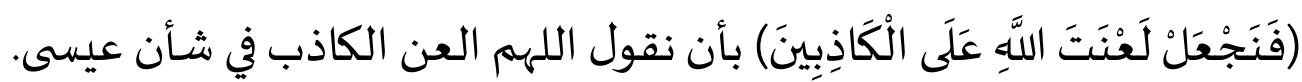
9. السياق يقص عن نهي القسم لعرضة البر والتقوى، تنظر الباحثة في تفسير الجلالين الشرح عن هذه الأية هو (وَلَا تَجْعَلُوا اللَّة) أي الحلف باه (عُرْضَةًا) علة

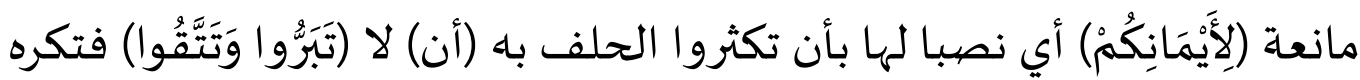
اليمين على ذلك يسن فيه الحنث ويكفر بخلافها على فعل البر ونحوه فهي طاعة (وَتُصنِلِحُوا بَيْنَ النَّاسِِ المعنى لا تمتنعوا من فعل ذكر من البر ونحوه إذا حلفتم عليه بل ائتوه وكفروا لأن سبب نزولها الامتناع من ذلك، ( • () السياق يقص عن قسم الكافرين، تعتمد الباحثة شرح هذا السياق على تفسير البغوي\} فَلا \{ أي: ليس الأمر كما يزعمون أههم مؤمنُون ثم لا يرضهون بحكمك، ثم استأنف القَسَمَ \}

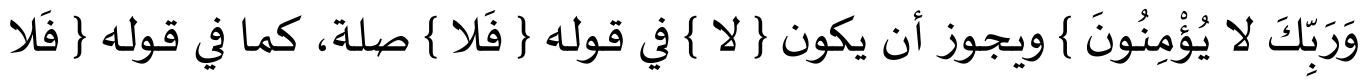




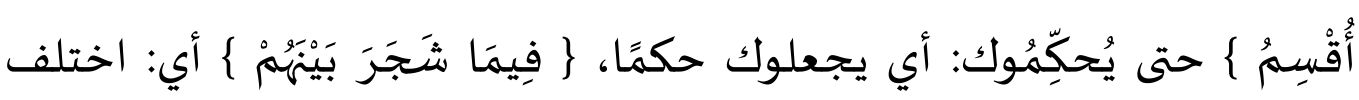
واختلط من أمورهم والْتَبَسَ عليهم حُكماه، ومنه الشجر لالتفاف أغصانهانه

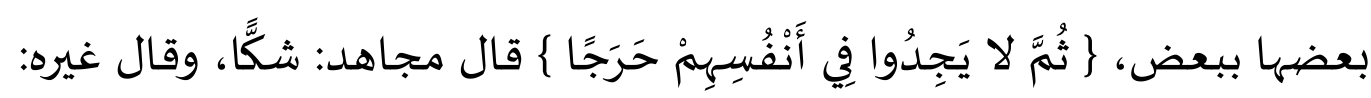

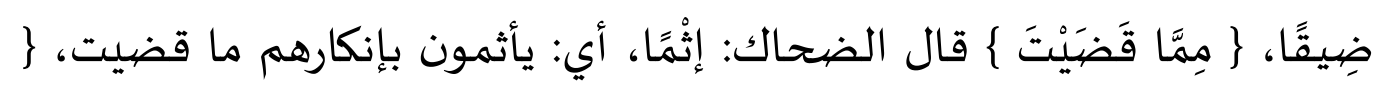

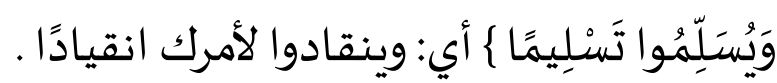

\section{خاتمت}

تحليل لفظ "القسم" ومرادفاته في السور المدنية، وصلت الباحثة إلى الخلاصة الأتية:

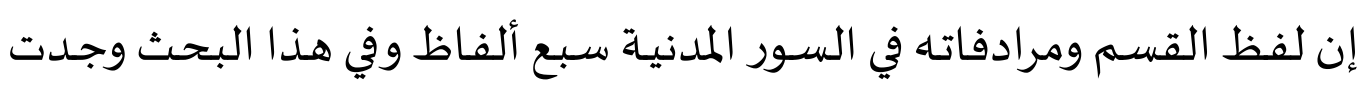

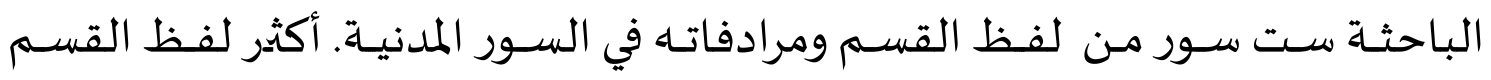
ومرادفاته هي لفظ أحلف ويحلفون وهي في عشر آيات من السور المدنية. إن فوائد لفظ القسم ومرادفاته في السور المدنية للتأكيد، وفي هذالبحثث تنظر

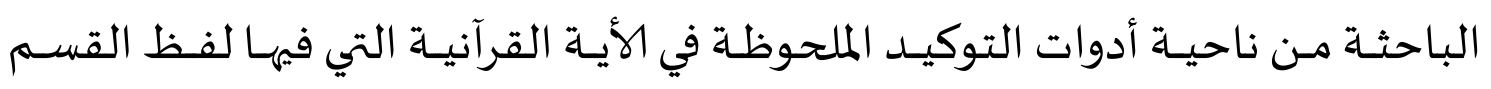
ومرادفاته في السور المدنية، تجد الباحثة ست سور من السور المدنية من الخبر الطلبي

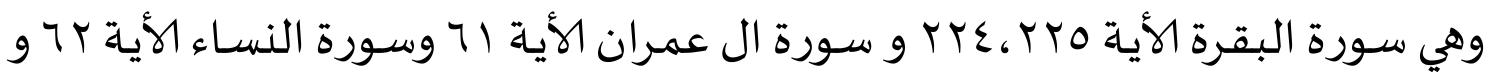

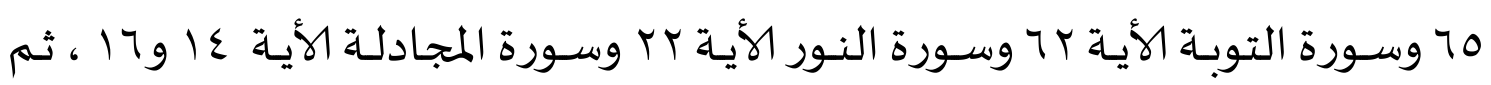
وجدت الباحثة الخبر الإنكاري في ثماني سور من السور المدنية وهي سورة البقرة الأية

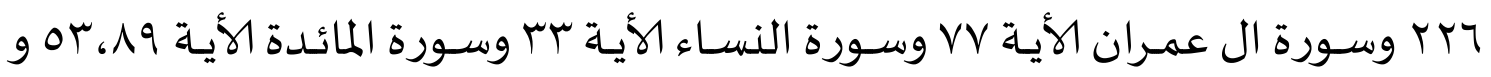

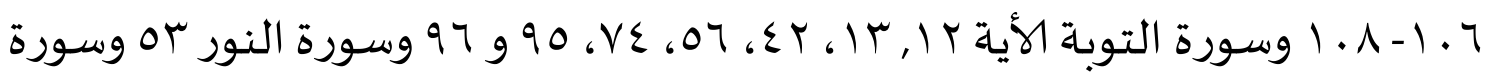
المجادلة الأية مل وسورة النافقون الأية بوسورة التحريم الأية r إن السياق الذي استخدم فيه لفظ القسم ومرادفاته في السور المدنية نوعين، (1) السياق من ناحية اللغة أو تسهى بالسياق اللغوي، تنظر الباحثة السياق اللغوي من الصيغة والإعراب وعناصر لفظ القسم ومرادفاته في السور المدنية و (T) السياق 
من ناحية مقتضى الحال أو تسمى بالسياق الموقفي ، تنظر الباحثة إلى مضشمون الأية التي فيها لفظ القسم ومرادفاته في السور المدنية

\section{قائمت المراجع}

القطان، مناع خليل. . . .ب. مباحث پِ علوم القرآن. الرياض: دار العلم الملايين.

المحلي، جلال الدين محمد و السيوطي، جلال الدين عبد الرحمن. دون السنة. تفسير

$$
\text { الجالالين. سوربايا :مكتبة الشيخ سالم بن سعد نبهان }
$$

عبيدات، ذوقان. 9 19V ا. البحث العلهي: مفهوهاه أدواته أساليبه. عمان: دار الفكر

$$
\text { علي الجارم ومصطفى أمـين.1999 ـ البالاغة الواضحة. لندن: دار المعارف }
$$$$
\text { عمر ، أحمد مختار. ب Y919. عله الدلالة. الكويت. مكتبة دار العربية. }
$$

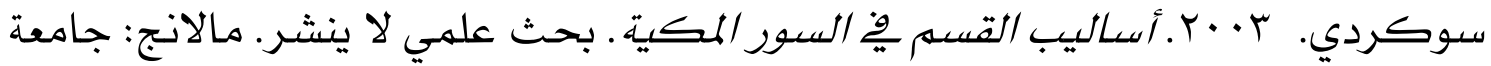

$$
\text { مالانج الحكومية }
$$

Ainin, Mohammad. 2010. Metodologi Penelitian Bahasa Arab. Malang: Hilal Pustaka.

Ainin, Mohammad. dan Imam Asrori. 2008. Semantik Bahasa Arab. Malang: Hilal Pustaka.

Al-Bighawi, المكتبة الشـاملة kata Fala warabbika, via software لفظ فلا وربك

Al-Bighawi, المكتبة kata Tahillata aimanikum, via software لفظ تحلة أيمانكم الشاملة

Djalal, Abdul. 2000. Ulumul Qur'an. Surabaya: Dunia Ilmu

Moleong, Lexy J. 2014. Metode Penelitian Kualitatif. Bandung: Remaja Rosdakarya

Mukhtar. 2013. Metode Praktis Penelitian Deskriptif Kualitatif. Jakarta: Ekstra Lintas Niaga 